\title{
The diagnostic accuracy of spot urine protein-creatinine ratio (UPCR) in quantification of proteinuria in women with preeclampsia
}

\author{
Dasaripalli Bharathi ${ }^{1}$, Sabita. $\mathbf{P}^{2 *}$, Nina V Kate ${ }^{3}$ \\ ${ }^{1}$ Post Graduate, ${ }^{2}$ Associate Professor, ${ }^{3}$ Chief Medical Officer, ${ }^{1-3}$ Dept. of Obstetrics and Gynecology, ${ }^{1,3}$ Rajiv Gandhi Government Women \\ and Children Hospital, Puducherry, ${ }^{2}$ Indira Gandhi Medical College and Research Institute, Puducherry, India
}

*Corresponding Author: Sabita. P

Email: sabita.kutty@gmail.com

Received: $9^{\text {th }}$ March, 2019

Accepted: $17^{\text {th }}$ April, 2019

\begin{abstract}
Introduction: Estimation of urinary excretion of protein is done by the standard method of collection of urine over 24- hours and the test sample is taken from this collection. Because of its technical difficulty there is the necessity to use quick, convenient and reliable method which is well correlates with $24-\mathrm{h}$ urine protein.

Aim: This study is carried out to compare the dipstick method and spot urine protein creatinine ratio (UPCR) with that of 24-h urine protein (24HUP) and also to determine the role of proteinuria in predicting the pregnancy outcome in preeclamptic patients.

Materials and Methods: We conducted this prospective analytical study in 209 antenatal women in whom 52 were with gestational hypertension and 157 were with preeclampsia. Pearson's correlation coefficient revealed the strength of correlation while the $p$ value less than 0.05 was considered to be statistically significant. Receiver-operator curve (ROC) was plotted to find the cut-off value of UPCR and dipstick in detecting significant proteinuria ( $\geq 300 \mathrm{mg} /$ day).

Results: The value of UPCR strongly correlated with 24 -h urine protein $(r=0.941, p<0.001)$. The cut-off value of 0.25 by UPCR method was considered as significant proteinuria. A strong positive correlation was found between $24 \mathrm{HUP}$ test and dipstick test $(r=0.759, p<0.001)$ results with a cut-off value of 1.5 to detect significant proteinuria.
\end{abstract}

Conclusions: Spot UPCR can be used as a rapid and reliable alternative method to 24-h urine protein in preeclamptic patients.

Keywords: Preeclampsia, Sspot UPR, 24-h urine protein and dipstick method.

\section{Introduction}

Hypertensive disorders constitute most common medical complications of pregnancy and also stand as an important cause of maternal and perinatal morbidity and mortality. In India, they contribute to $12 \%$ of maternal deaths. Among this subgroup of disorders, preeclampsia is the most threatening condition occurring in $2-10 \%$ of all pregnancies world wide. ${ }^{1}$ The diagnosis of preeclampsia is considered when the blood pressure is $\geq 140 / 90 \mathrm{~mm}$ of $\mathrm{Hg}$ in 2 sittings in an interval of 6 hours apart after $20^{\text {th }}$ week of pregnancy, with proteinuria $\geq 300 \mathrm{mg}$ in 24 - HUP test or $\geq 1+$ reading in dipstick test. ${ }^{2}$ The dipstick analysis done with visual reagent strips is a user-friendly, rapid and portable screening test; but as it has high false positive and false negative rates, the standard 24HUP test is carried out subsequently for confirmation. ${ }^{3}$ As urine protein concentration varies highly during the course of the day, ${ }^{4}$ the accuracy of random urine protein test (dipstick test) cannot be comparable with that of the 24HUP test. ${ }^{5,6}$ However 24HUP test is a cumbersome, inconvenient, timeconsuming process to collect urine and errors may occur due to incomplete collection. ${ }^{7}$ Frequent monitoring of urine protein is required in cases diagnosed as preeclampsia and it is a time taking process causing further delay in the management and sometimes the patients may deliver before completion of urine collection. Therefore, a reliable, quick and easily performable quantitative measurement of urinary protein excretion correlating well with the 24HUP test, is required for frequent monitoring and timely decisions and during pregnancy in preeclamptic mothers and also for decreasing their admissions.

Urinary creatinine is excreted at a fairly constant rate at stable glomerular filtration rate. Based on this observation in recent years, spot UPCR test has been suggested as a rapid test in quantifying significant proteinuria ${ }^{8-11}$. However, the accuracy of the test still remains unclear. Many studies have shown good correlation between UPCR test and 24HUP test $^{8,9}$ while few other studies found no proper correlation. ${ }^{10-}$ ${ }^{12}$ In many studies where UPCR was used, the predicting values of test results were not mentioned. ${ }^{8-10}$ Being an exclusive maternal and child health centre, our hospital has a high input of obstetric population and the incidence of hypertensive pregnancies. Our aim was to determine the diagnostic accuracy of UPCR in women with preeclampsia and to predict the outcome of pregnancy in relation to the severity of proteinuria.

\section{Aims and objectives}

1. Correlation of proteinuria estimated by $24 \mathrm{HUP}$ test with UPCR and to determine its accuracy.

2. Correlation between significant proteinuria by 24 HUP test and random urine protein (dipstick) test for proteinuria.

3. To determine the role of proteinuria as assessed by both the 24HUP (gold standard test) and the UPCR in predicting the outcome of pregnancy in $t$ these participants. 


\section{Material and Methods}

Our study was a prospective analytical study involving the pregnant women who were diagnosed to have preeclampsia (urine protein with dipstick test $1+$ or more) admitted in antenatal ward with the advice of modified bed rest. The exclusion criteria were the subjects with chronic hypertension, intrinsic renal disease, pathological vaginal discharge and urinary tract infection and hose planned for termination of pregnancy immediately.

The study was approved by the Scientific and Ethical Committee of the institute. After obtaining informed consent, detailed history including the demographic data, medical, obstetric and menstrual events and thorough clinical examination -both general and obstetric, were performed. Following this all the subjects were evaluated and treated as per the existing protocols of the obstetric unit.

\section{Procedure}

All were asked to collect 24-hour urine sample for determination of proteinuria. They were advised to collect urine at 8.00 am of a day till 8.00 am of the next morning. Random sample for UPCR test and dipstick test were collected in the next day morning after the 24-hour urine collection. The adequacy of urine collection was determined by the creatinine excretion. Subjects with inadequate urine sample and those with urinary tract infection were excluded from the final analysis. Only the subjects who had significant proteinuria i.e. $\geq 300 \mathrm{mg}$ in 24 hours urine sample were included in the final analysis.

\section{Methods}

\section{Urine dipstick test}

The dipstick tests were done using the UROCOLOR ${ }^{\mathrm{TM}} 2$ : SD urinalysis strips. Two random samples of urine collected by clean catch or from a urinary catheter and tested with a reagent strip; if the readings are noted as one plus or more when the urinary specific gravity is $<1030$ and $\mathrm{pH}$ being less than 8 , the condition is considered as significant proteinuria $(1+$ refers to the urinary albumin level as $0.3 \mathrm{~g} / \mathrm{L}$ and $2+$ to $1 \mathrm{~g} / \mathrm{L})$.

\section{HUP}

The urine was stirred to ensure homogeneity and a 6-mL aliquot sample was obtained. Analysis for protein was performed using a modified Fujita method (Sigma Diagnostics Microprotein-PR, procedure No. 611). The formula used to determine the amount of urinary protein $\left(\mathrm{U}_{\mathrm{p}}\right)$ based on the product of concentration of protein in the test sample $\left(\mathrm{T}_{\mathrm{p}}\right)$ and the total volume of urine $\left(\mathrm{U}_{\mathrm{v}}\right)$ is expressed as - Up (mg/day) = Uv (dl) $x \mathrm{Tp}(\mathrm{mg} / \mathrm{dl})$. Each sample was tested twice to calculate the mean value and each sample was paralleled with a low control and a high control. Comparison of this assay with other similar commercially available reagents shows a correlation coefficient of 0.997 for samples containing $1 \mathrm{mg} / \mathrm{dl}$ to 128 $\mathrm{mg} / \mathrm{dl}$. For those samples with significant proteinuria that exceed this value, the urine was diluted 1:10 with deionised water to maintain the sensitivity of the assay. When the 24 hour urine collection has the total protein of $300 \mathrm{mg}$ or greater, the condition is referred as significant proteinuria.

\section{Creatinine}

Modified Jaffe Method was used to estimate the urinary creatinine as per the instructions given in the Kit, Quimica Clinical Applicada S.A - Spain 2000. The principle behind this test is that when creatinine reacts with picric acid at alkaline $\mathrm{pH}$ values, it forms creatine alkaline picrate which has a distinct colour that can be measured photometrically. The serum creatinine was determined by using the same assay with $300 \mu \mathrm{L}$ of serum. Estimation of the creatinine clearance was calculated by using the formula - urine creatinine $(\mathrm{mg} / \mathrm{dl})$ x urine flow rate $(\mathrm{ml} / \mathrm{min})$ divided by serum creatinine $(\mathrm{mg} / \mathrm{dl})$. The tests were performed by a biochemist working in the laboratory of the hospital.

The various factors of outcome measured are:

1. Biochemical parameters: $24 \mathrm{hr}$ urine protein, random UCPR, Dipstick urine analysis,

2. Complications of pre-eclampsia:

Maternal: Eclampsia, abruption, HELLP syndrome, ARDS (Adult Respiratory Distress syndrome), Preterm labour, postpartum hemorrhage, other.

Fetal: IUD (Intrauterine Death), still birth, IUGR (Intrauterine Growth Retardation), birth asphyxia, Prematurity, Other

\section{Statistical Analysis}

13\%Data obtained were entered into MS Excel sheet. The measurements obtained in the study were continuous as well as discrete variables. We used SPSS software version 19.0 for statistical analysis. Categorical variables were analyzed and expressed in percentages and proportions. The association between various categorical variables was found using Chi square test. The continuous variables were analyzed and expressed in descriptive statistics like mean and $S D$. Point estimate of variability was done by standard error of mean. The inferential statistics was done and expressed by the application of test of significance to check and estimate if there is any significant difference of mean of various measurements. The test of significance between the dependent variable and other factors as independent variables was done using $P<0.05$ taken as significant level. Wherever required appropriate modality of graphical presentation was used. Pearson's correlation coefficient and Linear Regression were used to find correlation between the random UPCR and the 24-hour urine protein. Sensitivity and specificity were also calculated. At the end, a receiver operator characteristics (ROC) curve was drawn and area under curve was calculated. Spearman's rank order correlation coefficient and linear regression were used to find correlation between the dipstick test and the 24-hour urine protein; a receiver operator characteristics (ROC) curve was drawn and area under curve was calculated. 


\section{Observations and Results}

The present prospective study was conducted on 209 pregnant women who were presented with hypertension $(\geq 140 / 90 \mathrm{mmHg}$ ) and proteinuria (dipstick $\geq 1+$ ) after 20weeks of gestation. Among 209 cases 157 were with preeclampsia ( $24 \mathrm{hr}$ urine protein $\geq 300 \mathrm{mg}$ ), 52 cases were with gestational hypertension $(24 \mathrm{hr}$ urine protein $<300$ $\mathrm{mg})$. Only those 157 patients $(n=157)$ who had significant proteinuria ( $\geq 300 \mathrm{mg}$ in $24 \mathrm{hr}$ urine protein) were included in the final analysis.

The majority of the patients were in the age group of 20 to 30 years $(84.1 \%)$, more than half of the study group consisted of primigravida and two thirds of them being nulliparous (table 1). The period of gestation was $>37$ weeks in half of the study group. The status of preeclampsia was severe in 89 cases $(56.7 \%)$ and non-severe in 68 cases $(43.3 \%)$. (Table 2)

Correlation between significant proteinuria by 24HUP test and UPCR (Table 3): The mean and standard deviations for 24HUP test and UPCR are 611.35/0.5900 and 510.462 $/ 0.50483$ respectively for 209 subjects. There was a near perfect positive linear relationship between 24HUP test and UPCR. The value of $\mathrm{r}=0.941$ indicates a good linear relationship. Pearson's correlation test showed a positive correlation between 24HUP test and UPCR $(r=0.941)$ with a $\mathrm{P}<0.001$ which was strongly significant. If $24 \mathrm{HUP}$ is an independent variable \& the UPCR is a dependent variable, then the equation would be: PCR $=0.021+$ $(0.001 * 24$ HRUP). If UPCR is an independent variable \& the 24HUP is a dependent variable, then the equation would be: $24 \mathrm{HUP}=50.025+\left(951.475^{*} \mathrm{UPCR}\right)$. The ROC curve analysis showed that the optimal cut-off value of spot urine $\mathrm{P} / \mathrm{C}$ ratio to detect significant proteinuria $(>300 \mathrm{mg} /$ day $)$ was $\geq 0.25$, at which, the sensitivity was $100 \%$ and specificity was $90.60 \%$. Area under curve was 0.990 (good test).

Correlation between significant proteinuria by $24 H U P$ test and dipstick test (Table 4): A Spearman's rank-order correlation was run to determine the relationship between 24

- $\mathrm{h}$ urine protein and dipstick test. There was a strong, positive correlation between 24 - $\mathrm{h}$ urine protein and dipstick test, which was statistically significant $(\mathrm{rs}=0.759, \mathrm{p}$ $<0.001$ ). If dipstick grade is independent variable \& the $24 \mathrm{hr}$ urine protein is dependent variable, then the equation would be as follows: 24HUP $=-199.840+$ (435.832*Dipstick grade). If $24 \mathrm{hr}$ urine protein is independent variable \& the urine dipstick grade is dependent variable, then the equation would be as follows: Dipstick grade $=.972+(0.001 * 24 \mathrm{HUP})$. The ROC curve analysis showed that the optimal cut-off value of dipstick grade to detect significant proteinuria $(>300 \mathrm{mg} /$ day) was $>1.5$, at which, the sensitivity was $65.74 \%$ and specificity was $79.20 \%$. Area under curve was 0.742 .

Pregnancy outcome (maternal and fetal): (Table 5 and 6) Among 157 pre-eclampsia subjects 89 had severe variety 68 had non-severe pre-eclampsia and $68(43 \%)$ of all the study group had developed maternal complications, such as abruptio placenta, antepartum-eclampsia, HELLP syndrome, imminent eclampsia, papilledema, partial HELLP, postpartum-eclampsia, $\mathrm{PPH}$, preterm labour, pulmonary oedema in 11 cases with non-severe pre-eclampsia and 57 cases with severe pre-eclampsia; the most common were preterm labor, PPH and antepartum eclampsia in both the groups. Complications like abruptio placentae, HELLP syndrome, papilledema, postpartum eclampsia and pulmonary oedema were found exclusively in severe preeclampsia. The patients with severe preeclampsia had a greater number of emergency caesarean section (41/89) and preterm vaginal deliveries (35/89) compared to those with non-severe $(22 / 68,6 / 68)$ type with commonest indication being fetal distress and severe IUGR. Hence the number of full-term vaginal deliveries were more in non-severe type (36 vs 5). Among fetal complications, birth asphyxia (BA) and intrauterine growth retardation (IUGR) were the most common $(60 \%)$ overall and particularly in those with $24 \mathrm{HUP}>2 \mathrm{~g} /$ day, whereas in cases with $24 \mathrm{HUP} \leq 2 \mathrm{~g} /$ day, perinatal death $(75 \%)$

\section{Discussion}

The entity of hypertensive disorders of pregnancy is a major cause of maternal and perinatal mortality worldwide, of which preeclampsia remains the leading cause. Proteinuria with hypertension in pregnancy is associated with greater adverse maternal and fetal outcome. hence detection and frequent monitoring will be helpful in timely decisions. Therefore, reliable quantitative measurement of urinary protein excretion which will be quick and easy to perform and correlate well with the gold standard 24 HUP test is required. Age has an important influence on the incidence of hypertensive disorders of pregnancy with less risk of developing preeclampsia in the age group between 20 to 30 years, whereas the occurrence is more in the teen age and after 30 years of age during pregnancy in general population. ${ }^{13}$ In our study, the mean age of preeclampsia was 25.5 years and the maximum being between 20 to 30 years and hence the confounding effect of age factor has been eliminated in the present study; Majority 87/157 $(55.4 \%)$ were primigravida and $105 / 157(66.9 \%)$ were nulliparous women similar to the data published by Aggarwal $\mathrm{N}$ et al, ${ }^{14}$ but in Kumari A et al ${ }^{15}$ study majority of the patients were multigravidas. A systematic review of controlled trials by DuckittK et al $(2005)^{16}$ observed nulliparity (RR $2.91,95 \% \mathrm{CI}$ ) as an unadjusted relative risk factor for developing preeclampsia. The mean gestational age was $35 \pm 4$ weeks similar to previous studies, ${ }^{15,17,18}$ in Aggarwal $\mathrm{N}$ et $\mathrm{al}^{13}$ study the mean gestational age was 32 weeks which may be due to a greater number of severe cases.

In our study, the UPCR was well correlated with 24HUP with overall strength of correlation $r=0.941$ with $p$ value $<0.001$, similar to previous studies ${ }^{15,17,18}$ and such correlation $b$ will reflect the accuracy of UPCR. The optimal cut-off value of UPCR that predicts significant proteinuria in 24-hour urine sample ( $\geq 300 \mathrm{mg}$ ) was found to be $\geq 0.25$ as 
demonstrated by the area under ROC curve of 0.990 , at which the sensitivity was $100 \%$ and specificity was $90.6 \%$.

In Aggarwal N et al (2008) ${ }^{14}$ study the optimal cut-off value of spot UPCR that predicts significant proteinuria was $\geq 1.14$ with $72 \%$ sensitivity and $75 \%$ specificity which indicates that the UPCR is a poor predictor of 24-hour proteinuria. Few other studies. ${ }^{9,15}$ demonstrated that there was poor correlation between 24-HUP and UPCR at higher degree of proteinuria. These differences could be due to lack of uniformity and variable laboratory methods in estimation of proteinuria and variation in mean $24 \mathrm{HUP}$ values which precludes valid comparison among the studies. In our study the strong correlation may be due to majority of cases having proteinuria between 300 to $1000 \mathrm{mg} /$ day.

Moreover, the correlation between significant proteinuria by $24 \mathrm{HUP} \&$ dipstick test was statistically significant $\left(\mathrm{r}_{\mathrm{s}}=0.759, \mathrm{p}<0.001\right)$ in our study whereas with other studies ${ }^{17}$ the dipstick method failed to show significant correlation with the 24HUP test in the estimation of proteinuria; similar results of poor correlations have been seen in the studies involving patients of lupus nephritis and gestational hypertention, ${ }^{19,20}$ this may be due to the interobserver variation in noting the colour of the strip at different points of time could be one of the reasons. At times it is difficult to identify the colour accurately, especially when the colour is not exactly matching with any one (as $1+, 2+, 3+$, or $4+$ ) having intermediate hue. In our study 52 subjects out of 209 subjects had false positive dipstick test, as ours included a greater number of cases $(n=209)$ compared to the other studies and the correlation between dipstick and 24 HUP was high $(r=.759$, $p<0.001)$

Our study shows that the severity of adverse maternal outcome was maximum in subjects who had $>1 \mathrm{gm}$ protein in 24-hour urine and preterm delivery and eclampsia were being the most common complications. Among 157 preeclampsia subjects 85 patients had adverse foetal outcome and the perinatal mortality was maximum (11 cases out of 15 cases) in subjects who had 24HUP >1g. Waugh et al., (2005a)6 predicted adverse foetal outcome in patients with $24 \mathrm{HUP} \geq 500 \mathrm{mg}$ in their study. Hypertension together with proteinuria is associated with poor foetal outcome, small for gestational age pregnancies, perinatal mortality and maternal morbidity (Chan et al., 200557(20); Brown et al., 199658(21); Ferranzani et al., 199059;(22) Chua and Redman, 199260(23); Lin et al., 198261(24)). Newman et al., (2003)62 (25) found in a retrospective review that the magnitude of proteinuria, even when massive $(>10 \mathrm{~g} / 24$ hours), did not correlate with increased maternal or neonatal morbidity in preeclampsia. They concluded that neonatal morbidity appeared to be more a function of prematurity rather than massive proteinuria itself. In our study none of the cases had massive proteinuria. Only 4 cases had proteinuria $>2 \mathrm{gm}$. So, we could not conclude the relationship between the proteinuria $>2 \mathrm{gm}$ and maternal and foetal outcome.

Table 1:

\begin{tabular}{|c|c|c|c|}
\hline \multicolumn{2}{|c|}{ Demographic character } & No. patients $(\mathbf{n = 1 5 7})$ & \% \\
\hline \multirow{4}{*}{ Age } & $<20$ & 4 & 2.5 \\
\cline { 2 - 4 } & $20-30$ & 132 & 84.1 \\
\cline { 2 - 4 } & $>30$ & 21 & 13.4 \\
\hline Gravida & Primi & 87 & 55.4 \\
\cline { 2 - 4 } & Second & 42 & 26.8 \\
\cline { 2 - 4 } & Third & 22 & 14.0 \\
\cline { 2 - 4 } & fourth & 6 & 3.8 \\
\hline Parity & Nulliparous & 105 & 66.9 \\
\cline { 2 - 4 } & P1 & 40 & 25.5 \\
\cline { 2 - 4 } & P2 & 11 & 6.0 \\
\cline { 2 - 4 } & P3 & 1 & 6 \\
\hline
\end{tabular}

Table 2: Distribution of subjects as per gestational age

\begin{tabular}{|c|c|c|c|c|c|c|}
\hline Period of Gestation (weeks) & \multicolumn{7}{|c|}{ Pre-eclampsia } \\
\cline { 2 - 7 } & Non-severe & \multicolumn{2}{c|}{ Severe } & \multicolumn{2}{c|}{ Total } \\
\cline { 2 - 7 } & $\mathbf{N}$ & $\mathbf{\%}$ & $\mathbf{N}$ & $\mathbf{\%}$ & $\mathbf{N}$ & $\mathbf{\%}$ \\
\hline$<28$ & 1 & 1.5 & 9 & 10.1 & 10 & 6.4 \\
\hline 28 to 34 & 2 & 2.9 & 28 & 31.5 & 30 & 19.1 \\
\hline 34 to 37 & 10 & 14.7 & 28 & 31.5 & 38 & 24.2 \\
\hline$>37$ & 55 & 80.9 & 24 & 27 & 79 & 50.3 \\
\hline Total & 68 & 100 & 89 & 100 & 157 & 100 \\
\hline Chi-square $=47 \mathrm{df}=3 \mathrm{p}<0.001$ Strongly significant \\
\hline
\end{tabular}


Table 3: Correlation of 24HUP with UPCR and regression analysis

\begin{tabular}{|c|c|c|c|c|c|c|c|c|}
\hline & & orrel: & ion & & & 24HUP & & \\
\hline & HUP test & Pea & ion Corre & tion "r" & & 1 & & \\
\hline & & & Sig. (2-ta & & & & & \\
\hline & & & $\mathrm{N}$ & & & 209 & & \\
\hline & UPCR & Pea & son Corre & tion "r" & & $.941^{* *}$ & & \\
\hline & & & Sig. (2-ta & & & .000 & & \\
\hline & & & $\mathrm{N}$ & & & 209 & & \\
\hline & & & fficients: & ependen & t Variab & - UPCR & & \\
\hline & Model & & JSC & $\mathrm{SC}$ & $\mathrm{T}$ & $\begin{array}{l}\text { Sig. } \\
\text { Sig }\end{array}$ & $95.0 \%$ & for $B$ \\
\hline & & B & $\begin{array}{c}\text { Std. } \\
\text { Error }\end{array}$ & Beta & & & $\begin{array}{l}\text { Lower } \\
\text { Bound }\end{array}$ & $\begin{array}{l}\text { Upper } \\
\text { Bound }\end{array}$ \\
\hline 1 & (Constant) & .021 & .019 & & 1.137 & .257 & -.015 & .058 \\
\hline & 24HUP & .001 & .000 & .941 & 39.997 & .000 & .001 & .001 \\
\hline & & $\mathrm{Cos}$ & ficients & pendent & Variabl & $-24 \mathrm{HU}$ & & \\
\hline & Model & & US & & & $\mathrm{SC}$ & $\mathrm{T}$ & Sig. \\
\hline & & & 3 & SE & & Beta & & \\
\hline 1 & (Constant) & & 025 & 18.453 & & & 2.711 & 然 \\
\hline & UPCR & 95 & 475 & 23.789 & & .941 & 39.997 & .000 \\
\hline
\end{tabular}

**. Correlation is significant at the 0.01 level (2-tailed), $\mathrm{N}$ - Total number of patients, USC - Unstandardized coefficient, SC- Standardized coefficient, CI - confidence interval, SE Standard error

Table 4: Correlation of 24HUP with Dipstick - Spearman's rho and regression analysis

\begin{tabular}{|c|c|c|c|c|c|c|}
\hline \multicolumn{4}{|c|}{ Correlation } & 24HUP & \multirow{2}{*}{\multicolumn{2}{|c|}{$\begin{array}{c}\text { Dipstick } \\
.759^{* * *} \\
\end{array}$}} \\
\hline \multirow{3}{*}{\multicolumn{2}{|c|}{ 24HUP test }} & \multicolumn{2}{|c|}{ Correlation Coefficient } & 1.000 & & \\
\hline & & & & & \multicolumn{2}{|c|}{.000} \\
\hline & & \multicolumn{2}{|c|}{$\mathrm{N}$} & 209 & \multicolumn{2}{|c|}{209} \\
\hline \multirow{3}{*}{\multicolumn{2}{|c|}{ Dipstick }} & \multicolumn{2}{|c|}{ Correlation Coefficient } & $.759^{* *}$ & \multicolumn{2}{|c|}{1.000} \\
\hline & & \multicolumn{2}{|c|}{ Sig. (2-tailed) } & .000 & \multirow{2}{*}{\multicolumn{2}{|c|}{209}} \\
\hline & & \multicolumn{2}{|c|}{$\mathrm{N}$} & 209 & & \\
\hline \multicolumn{7}{|c|}{ Coefficients: Dependent Variable - Dipstick grade } \\
\hline \multirow{2}{*}{\multicolumn{2}{|c|}{ Model }} & & & SC & \multirow[t]{2}{*}{$\mathrm{T}$} & \multirow[t]{2}{*}{ Sig } \\
\hline & & B & SE & Beta & & \\
\hline \multirow[t]{2}{*}{1} & (Constant) & .972 & .061 & & 15.897 & .000 \\
\hline & 24HUP & .001 & .000 & .796 & 18.947 & .000 \\
\hline \multicolumn{7}{|c|}{ Coefficients: Dependent Variable - 24HUP } \\
\hline \multirow{2}{*}{\multicolumn{2}{|c|}{ Model }} & \multicolumn{2}{|c|}{ USC } & SC & \multirow[t]{2}{*}{$\mathrm{T}$} & \multirow[t]{2}{*}{ Sig. } \\
\hline & & $\mathrm{B}$ & $\mathrm{SE}$ & Beta & & \\
\hline \multirow[t]{2}{*}{1} & (Constant) & -199.840 & 47.867 & & -4.175 & .000 \\
\hline & Dipstick & 435.832 & 23.003 & .796 & 18.947 & .000 \\
\hline
\end{tabular}

**. Correlation is significant at the 0.01 level (2-tailed), N- Total number of patients, USC- Unstandardized coefficient, SC Standardized coefficient, CI - confidence interval, SE Standard error

Table 5:

\begin{tabular}{|c|c|c|c|c|c|}
\hline \multicolumn{2}{|c|}{} & \multicolumn{4}{|c|}{ M hours urine protein(mg/day) } \\
\cline { 3 - 6 } \multicolumn{2}{|l|}{ Maternal complications } & $\mathbf{2 0 0 0}$ & $\mathbf{1 0 0 0}$ to 2000 & $\mathbf{3 0 0}$ to 1000 & Total \\
\hline Abruptio placenta & $\mathrm{N}(\%)$ & $0(0)$ & $4(66.7 \%)$ & $2(33.3 \%)$ & $6(100 \%)$ \\
\hline AP-Eclampsia & $\mathrm{N}(\%)$ & $1(11.1 \%)$ & $7(77.8 \%)$ & $1(11.1 \%)$ & $9(100 \%)$ \\
\hline HELLP syndrome & $\mathrm{N}(\%)$ & $2(66.7 \%)$ & $1(33.3 \%)$ & $0(0)$ & $3(100 \%)$ \\
\hline Imminent eclampsia & $\mathrm{N}(\%)$ & $0(0)$ & $3(42.9 \%)$ & $4(57.9 \%)$ & $7(100 \%)$ \\
\hline Papilledema & $\mathrm{N}(\%)$ & $0(0)$ & $1(100 \%)$ & $0(0 \%)$ & $1(100 \%)$ \\
\hline Partial HELLP & $\mathrm{N}(\%)$ & $0(0)$ & $1(50 \%)$ & $1(50 \%)$ & $2(100 \%)$ \\
\hline Postpartum eclampsia & $\mathrm{N}(\%)$ & $0(0)$ & $1(100 \%)$ & $0(0)$ & $1(100 \%)$ \\
\hline PPH & $\mathrm{N}(\%)$ & $0(0)$ & $1(14.3 \%)$ & $6(85.7 \%)$ & $7(100 \%)$ \\
\hline
\end{tabular}




\begin{tabular}{|c|c|c|c|c|c|}
\hline Preterm delivery & $\mathrm{N}(\%)$ & $0(0)$ & $6(19.4 \%)$ & $25(80.6 \%)$ & $31(100 \%)$ \\
\hline Pulmonary oedema & $\mathrm{N}(\%)$ & $0(0)$ & $1(100 \%)$ & $0(0)$ & $1(100 \%)$ \\
\hline No complications & $\mathrm{N}(\%)$ & $1(1.1 \%)$ & $7(7.9)$ & $81(91 \%)$ & $89(100 \%)$ \\
\hline Total & $\mathrm{N}(\%)$ & $4(2.5 \%)$ & $33(21 \%)$ & $120(76.4 \%)$ & $157(100 \%)$ \\
\hline
\end{tabular}

Table 6: $\mathrm{F}$ et al complication relation

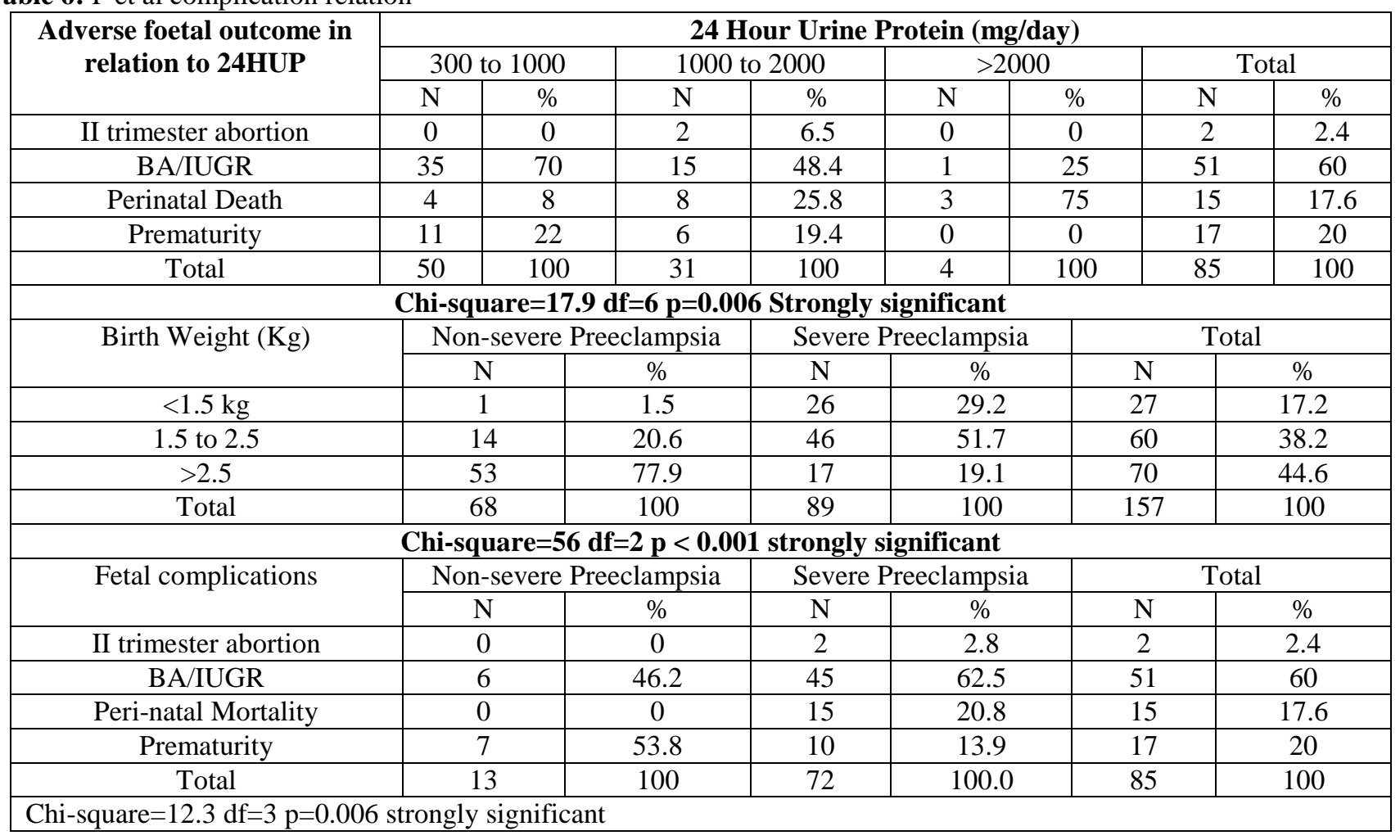

\section{Conclusion}

From the results of the present study and review of the earlier studies it can be concluded that, the use of spot UPCR test as alternative test to 24-HUP test can be much more cost effective as shown with many other studies previously. We have also found the 24-hour urine collection to be cumbersome and inconvenient for pregnant women. The dipstick method because of its simplicity and cost may be continued to be used as initial screening method. There was a poor maternal and perinatal outcome in those women with proteinuria $>1 \mathrm{gm}$.

\section{Conflict of Interest: None.}

\section{References}

1. Kayode O. Osungbade and Olusimbo K. Ige. Public Health Perspectives of Preeclampsia in Developing Countries: Implication for Health System Strengthening Journal of Pregnancy. 2011, Article ID 481095, 6 pages.

2. Cunningham FG, Leveno KJ, Bloom ST, Hauth JC, Rouse DJ, Spong CY. Williams obstetrics, McGraw-HILL Medical publishing Division, International Edition, 2010; $23^{\text {rd }}$ Edition, 706-9.

3. Price CP, Newall RG, Boyd JC. Use of protein: Creatinine ratio measurements on random urine samples for prediction of significant proteinuria: a systematic review. Clin Chem 2005;51:1577-86.

4. Kieler H, Zettergren T, Svensson H, Dickman PW, Larsson A. Assessing urinary albumin excretion in pre-eclamptic women: which sample touse? BJOG 2003;110:12-17.

5. Meyer NL, Mercer BM, Friedman SA, Sibai BM. Urinary dipstick protein: a poor predictor of absent or severe proteinuria. Am J Obstet Gynecol 1994;170:137-41.

6. Waugh JJ, Bell SC, Kilby MD, Blackwell CN, Seed P, Shennan AH et al., Optimal bedside urinalysis for the detection of proteinuria in hypertensivepregnancy: a study of diagnostic accuracy. BJOG 2005; 112:412-17.

7. Côté AM, Firoz T, Mattman A, Lam EM, von Dadelszen P, Magee LA et al. The 24 hour urine collection: gold standard or historical practice? Am J Obst Gynecol 2008; 199:e1-6.

8. Boler L, Zbella EA, Gleichea N. Quantitation of proteinuria in pregnancy by use of single voided urine samples. Obstet Gynecol 1987;70:99-100.

9. 9.Jaschevatzky OE, Rosenberg RP, Shalit A, Zondea HB, Grunstein S. Protein/creatinine ratio in random urine specimens for quantitation of proteinuria in preeclampsia. Obstet Gynecol 1990;75:604-6.

10. Durnwald C, Mucer B. A prospective comparison of total protein/creatinine ratio versus 24 hour urine protein in women with suspected preeclampsia. Am J Obstet Gynecol 2003;189:848-52.

11. Al RA, Baykal C, Karacay O, Geyik PO, Altun S, Dolen I et al. Random urine protein-creatinine ratio to predict proteinuria 
in new onset mild hypertension in late pregnancy. Obstet Gynecol 2004;104:367-371.

12. Lindow SW, Davey DA. The variability of urinary protein and creatinine excretion in patients with gestational proteinuric hypertension. Br J Obstet Gynaecol 1992;99:869-72.A

13. Kumari N, Dash K, Singh R. Relationship between Maternal Age and Preeclampsia. IOSR J Dent Med Sci 2016;15(12):5557.

14. Aggarwal N, Suri V, Soni S, Chopra V, Kohli HS. A Prospective Comparison of Random Urine Protein-Creatinine Ratio vs 24-hour Urine Protein in Women with Preeclampsia. Medscape J Med 2008;10(4):98.

15. Kumari A, Singh A, Singh R. Evaluation of rapid diagnostic methods of urinary protein estimation in patients of preeclampsia of advanced gestational age. J Obstet Gynecol India 2013;63(5):306-10.

16. Duckitt K, Harrington D. Risk factors for pre-eclampsia at antenatal booking: systematic review of controlled studies. $\mathrm{Br}$ Med J 2005;330:565-71.

17. Park JH, Chung D, Cho HY, Kim YH, Son GH, Park YW et al., Random urine protein/creatinine ratio readily predicts proteinuria in preeclampsia. Obstet Gynecol Sci 2013;56(1):814.

18. Methaauttaphong L, Siwadul T. The accuracy of using random urinary protein-to-creatinine ratio for prediction of significant proteinuria for diagnosis of preeclampsia in hypertensive pregnancies. J Obstet Gynecol Thai 2008;16:21-29.

19. Waugh J, Bell SC, Kilby M, Lambert P, Shennan A, Halligan A et al. Effect of the concentration and biochemical assay on the accuracy of urine dipsticks in hypertensive pregnancies. Hypertens Pregnancy 2001;20:205-21
20. Gangaram R, Ojwang PJ, Moodley J, Maharaj D. The accuracy of urine dipsticks as a screening test for proteinuria in hypertensive disorders of pregnancy. Hypertens Pregnancy 2005;24:117-23.

21. Chan P, Brown M, Simpson JM, Davis G. Proteinuria in preeclampsia: how much matters? Br J Obstet Gynaecol 2005;112:280-85.

22. Brown MA, Buddle ML. Hypertension in pregnancy: maternal and fetal outcomes according to laboratory and clinical features. MJA 1996;165:360-65.

23. Ferranzani S, Caruso A, de Carolis S, Martino N, Mancuso S. Proteinuria and outcome of 444 pregnancies complicated by hypertension. Am J Obstet Gynecol 1990;162:366-71.

24. Chua S, Redman CWG. Prognosis for pre-eclampsia complicated by $5 \mathrm{~g}$ or more of proteinuria in 24 hours. Eur $J$ Obstet Gynaecol Reprod Biol 1992;43:9-12.

25. Lin CC, Lindheimer MD, River P, Moawed A. Fetal outcome in hypertensive disorders of pregnancy. Am J Obstet Gynecol 1982;142:255-9.

26. Newman MG, Robichaux AG, Stedman CM, Jaekle RK, Fontenot TM, Dotson T et al., Perinatal outcomes in preeclampsia that is complicated by massive proteinuria. Am $J$ Obstet Gynecol 2003;188:264-8.

How to cite this article: Bharathi D, Sabita P, Kate NV, The diagnostic accuracy of spot urine protein-creatinine ratio (UPCR) in quantification of proteinuria in women with preeclampsia. Indian J Obstet Gynecol Res 2019;6(2):185191. 